\title{
An Environmental Friendly Flow-Injection Procedure for On Line Extraction and Spectrophotometric Determination of Gossypol in Cottonseed Meal
}

\author{
Bianca Daminato, Marcos Y. Kamogawa* and Wanessa R. Melchert \\ Escola Superior de Agricultura “Luiz de Queiroz”, Universidade de São Paulo, \\ PO Box 9, 13418-970 Piracicaba-SP, Brazil
}

\begin{abstract}
A fast, simple and inexpensive procedure is described for the determination of gossypol in cottonseed meal. The procedure is based on a flow injection analysis system and a complexation reaction with spectrophotometric detection at $620 \mathrm{~nm}$. A fluidized bed column was used to implement the on line that was coupled to the extraction flow system in order to analyze the solid samples directly. A linear response was observed from 0.96 to $3.85 \mathrm{mmol} \mathrm{L}^{-1}$, and the detection limit, the coefficient of variation and the sampling rate were estimated at $100 \mu \mathrm{mol} \mathrm{\textrm {L } ^ { - 1 }}$ (99.7\% confidence level), $1.90 \%(\mathrm{n}=20)$ and $30 \mathrm{~h}^{-1}$, respectively. The reagent consumption was $1.08 \mathrm{mg}$ of $\mathrm{Fe}\left(\mathrm{NO}_{3}\right)_{3}$, with a volume of $20 \mathrm{~mL}$ of effluent per determination. Analyses of the results of commercial samples were consistent with through the official procedure of detoxification of cottonseed meal as described by American Oil Chemists' Society (AOCS) at the $95 \%$ confidence level.
\end{abstract}

Keywords: gossypol, flow analysis, spectrophotometric detection

\section{Introduction}

Cottonseed meal is obtained in the oil extraction process. It is high in protein, fiber and minerals and can be used as a fertilizer and animal feed. However, its use is limited by the presence of the polyphenolic yellow compound known as gossypol. ${ }^{1}$ Gossypol (2,2'-bis(8-formyl-1,6,7-trihydroxy-5-isopropyl3 -methylnaphthalene) is a toxic pigment that occurs in various parts of cotton plants. ${ }^{2}$ It is undesirable for different animal species, especially for poultry and swine. ${ }^{3}$

Several procedures have been described in the literature for the analysis of gossypol, including procedures based on high performance liquid chromatography (HPLC), ${ }^{4,5}$ enzyme-linked immunosorbent assay ${ }^{6}$ and Fourier transform infrared spectroscopy (FTIR). ${ }^{7}$ The spectrophotometric determination of gossypol can be performed using 3-amino-1-propanol and its subsequent complexation with iron(III), forming a green-colored complex with maximum absorption at $620 \mathrm{~nm}$. To extract the analyte from the cottonseeds, $80 \mathrm{~mL}$ of hexane-isopropyl alcohol is used per determination. ${ }^{2}$ Another procedure is based on secondderivative ultraviolet spectrophotometry and it involves the extraction of free gossypol using aqueous acetone,

*e-mail: kamogawa@usp.br hydrolysis of the soluble-bound forms with hydrochloric acid and the partitioning of the pure compound into chloroform. The proposed method showed good precision (4.0\%), but a large amount of organic solvents was used (50 $\mathrm{mL}$ acetone and $50 \mathrm{~mL}$ chloroform) and a lot of time was spent $(2 \mathrm{~h})$ on each sample. ${ }^{8}$ These drawbacks hinder the use of these procedures for routine analysis.

Flow-injection systems (FIA) have been employed especially for the mechanization of analytical procedures in order to minimize the analyst intervention and enhance the number of samples processed by time and improving precision. In the preparation of samples, FIA can be used to minimize risks of sample contamination and amounts of organic solvents, as well as reduce costs of analysis. These systems also show great potential for the development of greener analytical procedures, with the replacement of toxic reagents, ${ }^{9-11}$ the minimization of reagent consumption with multicommutation systems ${ }^{12,13}$ and standstill reagents, ${ }^{14,15}$ the reuse of waste generated, ${ }^{16,17}$ and the treatment of waste. ${ }^{18-20}$

A flow procedure based on chemiluminescence ${ }^{1}$ was developed, exploiting the reaction of luminol with ferricyanide in a sodium hydroxide medium sensitized by gossypol. The method was applied to pharmaceutical preparations and cottonseeds. An amount of the sample powder was dissolved in acetone and evaporated to dryness 
under a nitrogen stream. Hydrochloric acid $\left(0.01 \mathrm{~mol} \mathrm{~L}^{-1}\right)$ was directly added to the residue, and the amount of analyte was then determined.

In this work, a simple spectrophotometric flow system for the extraction of gossypol and the determination of cottonseeds is proposed. The extraction was conducted with a fluidized bed column and diluted on line.

\section{Experimental}

\section{Apparatus}

The flow system was constructed with a sliding-bar commutator, $0.7 \mathrm{~mm}$ i.d. polyethylene tubing and Perspex joint points. An Ismatec peristaltic pump (Ismatec, Wertheim, Germany, model REGLO Digital) equipped with Tygon ${ }^{\circledR}$ tubes was used to propel fluid. Spectrophotometric measurements were carried out with a multichannel CCD spectrophotometer (Ocean Optics, Dunedin, FL, USA; model USB2000) with a tungsten-halogen light source (Ocean Optics, Dunedin, FL, USA; model LS-1). Optical fibers $(100$ or $600 \mu \mathrm{m})$ were employed to transport the radiation. A $1 \mathrm{~cm}$ optical path (80 $\mu \mathrm{L}$ internal volume, $0.3 \mathrm{~cm}$ i.d.) quartz flow cell (Hellma, Plainview, NY, USA) was also employed. The software furnished by the fabricant of the multichannel spectrophotometer was employed for data acquisition.

The fluidized bed column was made from acrylic and was $5 \mathrm{~cm}$ long and $0.4 \mathrm{~cm}$ i.d. Cotton was added to the bottom of the column to hold the seed, and a filter support (Millipore Swinnex) containing $0.45 \mu \mathrm{m}$ cellulose acetate membrane was placed at the top to retain the particulate material. Each sample was milled in Wiley mill with $1 \mathrm{~mm}$ screen sieve, homogenized and added $(25 \mathrm{mg})$ in its own column being discarded after use.

The debubbler (Ismatec) consisted of a cylindrical tube with holes on one side where was placed a Teflon tape permeable to gases.

\section{Flow diagram and procedure}

The fluidized bed column and flow manifold are shown in Figure 1. The column was positioned in the sample inset of the flow diagram, and an extraction solution $\left(1.1 \mathrm{~mL} \mathrm{~min}^{-1}\right)$ was inserted into the diluent solution $\left(8.7 \mathrm{~mL} \mathrm{~min}^{-1}\right)$ at the Perspex joint point. After extraction and dilution, the solution containing gossypol was inserted into the sample loop $\left(\mathrm{L}_{1}\right)$, as shown in the diagram in Figure 1. The extraction diluent solution and the reagent $(\mathrm{R})$ were then aspirated simultaneously to fill the loops $\left(\mathrm{L}_{1}: 30 \mathrm{~cm}\right.$ and $\left.\mathrm{L}_{2}: 20 \mathrm{~cm}\right)$. In the alternative injector position, the solutions were inserted into the carrier stream, and the sample zone was transported through the $100 \mathrm{~cm}$ long coil heading to the flow cell, where the spectrophotometric measurements $(620 \mathrm{~nm})$ took place. A debubbler was employed between the reactor coil and the flow cell to prevent bubbles from forming in the ethanol solutions.

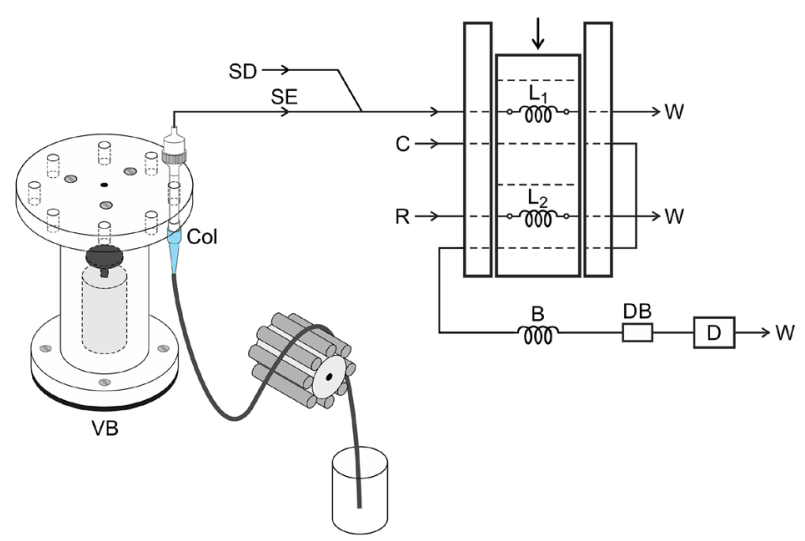

Figure 1. Flow analyses system diagram. VB: vibratory shaker; Col: fluidized bed column; SE: extraction solution, $1.1 \mathrm{~mL} \mathrm{~min}^{-1}$; $\mathrm{SD}$ : diluent solution, $8.7 \mathrm{~mL} \mathrm{~min}{ }^{-1}$; R: reagent, $1.8 \mathrm{mmol} \mathrm{L}^{-1} \mathrm{Fe}\left(\mathrm{NO}_{3}\right)_{3}$ in $0.16 \mathrm{~mol} \mathrm{~L}^{-1} \mathrm{HCl}$; $\mathrm{C}$ : carrier stream, $1.7 \mathrm{~mL} \mathrm{~min}^{-1}$; B: $100 \mathrm{~cm}$ coiled reactor; $\mathrm{L}_{1}$ : sample loop, $150 \mu \mathrm{L} ; \mathrm{L}_{2}$ : reagent loop, $100 \mu \mathrm{L}$; DB: debubbler; D: spectrophotometer and W: waste.

The fluidized bed column was under constant stirring using a homemade vibratory shaker (DC motor with eccentric axis) for a better interaction between the extraction solution and the cottonseed meal. The spectrophotometer software was employed for data acquisition, and measurements were based on peak height and carried out in triplicate.

For accuracy assessment, the procedure described by the American Oil Chemist's Society ${ }^{21}$ was adopted as a reference for comparing the results of the analyses. It consists of extracting gossypol with $50 \mathrm{~mL}$ acetone, shaking for $60 \mathrm{~min}$ and react with $p$-anisidine in isopropyl alcohol. The compound formed had maximum absorption at $447 \mathrm{~nm}$.

\section{Reagents and solutions}

All solutions were prepared with analytical-grade chemicals and distilled-deionized water. The reference solutions were prepared in the range $0.96-3.85 \mathrm{mmol} \mathrm{L}^{-1}$ gossypol (Sigma-Aldrich) by dilution of a $3.85 \mathrm{mmol} \mathrm{L}^{-1}$ stock solution prepared in ethanol $(55 \% \mathrm{v} / \mathrm{v})$. The reagent was a solution containing $1.8 \mathrm{mmol} \mathrm{L}^{-1} \mathrm{Fe}\left(\mathrm{NO}_{3}\right)_{3}$ (dissolving appropriate amounts of these reagents in ethanol $(55 \% \mathrm{v} / \mathrm{v})$ ) and $0.16 \mathrm{~mol} \mathrm{~L}^{-1}$ hydrochloric acid. An ethanol 55\% (v/v) solution was employed as a carrier, extraction and diluent solution. 


\section{Results and Discussion}

The spectrophotometric determination was based in the generation of the green complex by gossypol (Figure 2) and iron(III) with maximum absorption at $620 \mathrm{~nm}$.

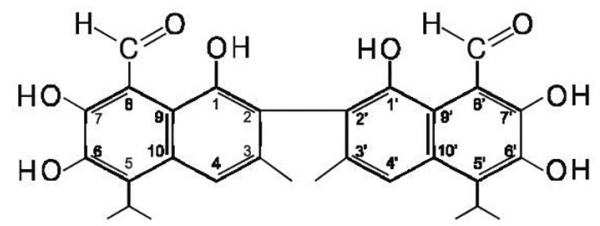

Figure 2. Molecular structure of gossypol.

In previous work that used the same complexation reaction, ${ }^{2}$ a solution containing 3-amino-1-propanol, acetic acid and dimethylformamide was used to assist in stabilizing the complex. However, in the proposed procedure, non-significant differences were observed in the analytical signals due to the stability of the complex. Furthermore, the use of this stabilizer solution would cause disturbances resulting in spectrophotometric measurements of the Schlieren ${ }^{22}$ effect. In the on line extraction, acetone was replaced by ethanol $55 \%(\mathrm{v} / \mathrm{v})$ because it is a more environmentally friendly solvent. To avoid problems with bubbles (Figure 3), a debubbler was inserted between the reactor and the flow cell (Figure 1).

\section{System optimization}

The optimizations of the hydrodynamic parameters, loops length (sample and reagent) and reactor coil length were performed using the univariate method in triplicate and considering precision, reagent consumption and the magnitude of the analytical signal. A summary of the ranges studied and the selected values is presented in Table 1.

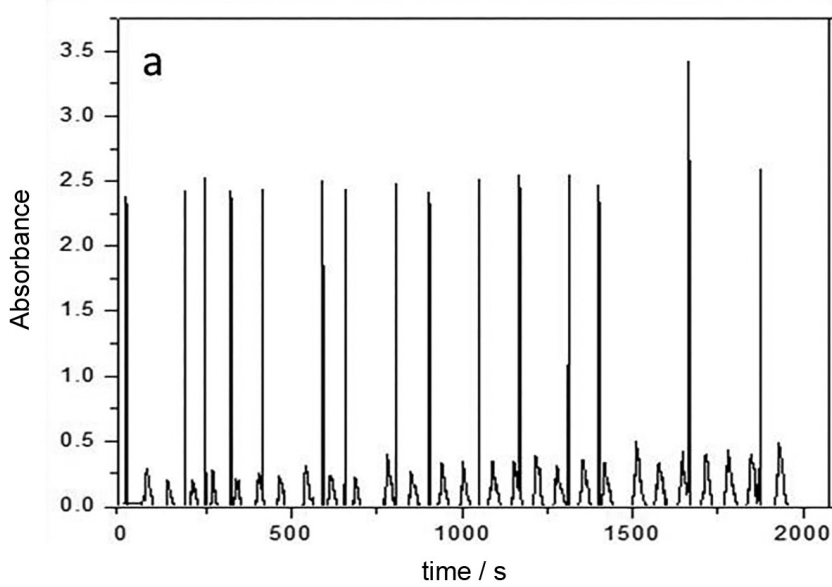

Table 1. Ranges studied and optimized conditions for gossypol extraction and determination

\begin{tabular}{lcc}
\hline Parameter & $\begin{array}{c}\text { Range } \\
\text { studied }\end{array}$ & $\begin{array}{c}\text { Selected } \\
\text { value }\end{array}$ \\
\hline Sample loop $\left(\mathrm{L}_{1}\right) / \mu \mathrm{L}$ & $25-500$ & 150 \\
Reagent loop $\left(\mathrm{L}_{2}\right) / \mu \mathrm{L}$ & $25-500$ & 100 \\
Reactor coil $(\mathrm{B}) / \mathrm{cm}$ & $50-150$ & 100 \\
Cottonseed meal mass / mg & $25-150$ & 25 \\
Extraction solution flow rate / $\left(\mathrm{mL} \mathrm{min}^{-1}\right)$ & $0.6-2.9$ & 1.1 \\
Carrier stream flow rate / $\left(\mathrm{mL} \mathrm{min}^{-1}\right)$ & $0.6-2.9$ & 1.7 \\
\hline
\end{tabular}

The loops length $300 \mu \mathrm{mol} \mathrm{L}{ }^{-1}$ gossypol in ethanol $(55 \% \mathrm{v} / \mathrm{v})$ and $1.8 \mathrm{mmol} \mathrm{L}^{-1} \mathrm{Fe}\left(\mathrm{NO}_{3}\right)_{3}$ in $0.16 \mathrm{~mol} \mathrm{~L}^{-1} \mathrm{HCl}$ were evaluated individually within a range of $5-100 \mathrm{~cm}$ (25-500 $\mu \mathrm{L})$. As expected, the analytical signal gradually increased with the increasing sample loop length, and the blank signal showed no significant difference. The reagent loop length up to $350 \mu \mathrm{L}$ did not have a great effect on the analytical signal because the reagent was in excess of the analyte (> 50-fold). Above $350 \mu \mathrm{L}(70 \mathrm{~cm})$, the interpenetration of the sample and reagent zones was low, disfavoring the chemical reaction. However, the best ratio between analytical signal and blank signal was when the 30 and $20 \mathrm{~cm}(150$ and $100 \mu \mathrm{L})$ loops were used for the sample and the reagent, respectively.

The effects of the carrier stream flow rates $(0.6$ and $\left.2.9 \mathrm{~mL} \mathrm{~min}^{-1}\right)$ and the reactor coil lengths (50 and $150 \mathrm{~cm}$ ) were evaluated individually. Higher analytical signals were obtained with smaller reactor lengths and higher flow rates. This is because larger reactor coil lengths and smaller flow rates affect the sample zone residence time, favoring of the dispersion effect. The $1.7 \mathrm{~mL} \mathrm{~min}^{-1}$ flow rate and the $100 \mathrm{~cm}$ reactor coil length presented an adequate response and good reproducibility, and they were selected for these reasons.

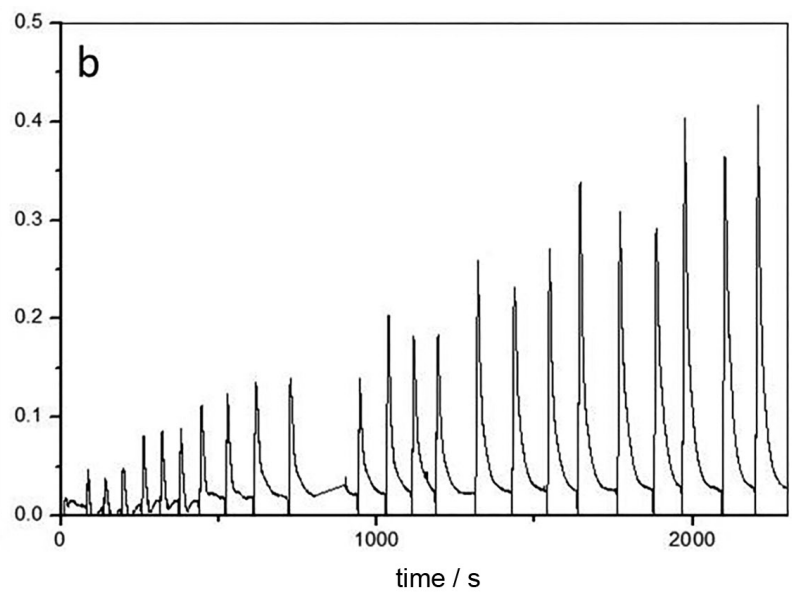

Figure 3. Transient analytical signals for reference solutions in the range $0.03-0.3 \mathrm{mmol} \mathrm{L}^{-1}$ gossypol (a) without and (b) with debubbler. 
For the extraction of gossypol from the cottonseed meal, a solution of ethanol $55 \%(\mathrm{v} / \mathrm{v})$ was evaluated; it was already being used in the FIA system as the carrier stream in optimization studies. The experiments were carried out in batch mode, and quantitative extractions $(97.0 \pm 0.0210 \%$ for replicates) were obtained, demonstrating the viability of using ethanol $55 \%(\mathrm{v} / \mathrm{v})$ as the extraction solution.

In order to decrease the amount of solvent and increase the sampling rate, fluidized bed columns were employed for the gossypol extraction (Figure 1). The extraction was performed in triplicate, and the recovery was estimated at $66.5 \pm 0.430 \%$. Thus, to improve the extraction, a vibrating apparatus was employed in the fluidized bed column. The gossypol recovery was estimated at $92.7 \pm 0.280 \%$ for triplicate, demonstrating the viability of using the fluidized bed column with mechanical vibratory stirring.

The flow rate of the extraction solution $\left(0.6-2.9 \mathrm{~mL} \mathrm{~min}^{-1}\right)$ and the cottonseed meal mass $(25-125 \mathrm{mg})$ in the fluidized bed column were optimized in order to improve contact between the two and to avoid preferential pathways. The recovery in the flow rate studies were estimated at $98.3 \pm 0.410 ; 97.8 \pm 0.302 ; 94.1 \pm 0.468$ and $93.9 \pm 0.561 \%$ for $0.6,1.1,1.7$ and $2.6 \mathrm{~mL} \mathrm{~min}{ }^{-1}$, respectively. It was possible that, for smaller flow rates, the recovery was higher due to the higher contact time between the extraction solution and the cottonseed meal, thus favoring gossypol extraction. However, the effect of the cottonseed meal mass on the column did not significantly affect the recovery of gossypol (values estimated above 98\%). Thus, $1.1 \mathrm{~mL} \mathrm{~min}^{-1}$ and $25 \mathrm{mg}$ were employed for the flow rate of the extraction solution and the cottonseed meal mass, respectively.

According to the literature, ${ }^{23}$ the average level of total gossypol present in cottonseed meal is approximately $1.0 \%(\mathrm{~m} / \mathrm{m})$, which was the value adopted for the studies with the addition of $0.25 \mathrm{mg}$ of gossypol in $25 \mathrm{mg}$ of meal which resulted in a final concentration of $2.41 \mathrm{mmol} \mathrm{L}^{-1}$ gossypol. This concentration would be 10 -fold the linear response of the calibration curve. Then, to perform the on line extraction a confluence point in the FIA system was inserted with a diluent solution of ethanol $(55 \% \mathrm{v} / \mathrm{v})$ at a flow rate of $8.7 \mathrm{~mL} \mathrm{~min}^{-1}$. After extraction and dilution, the solution containing the gossypol was inserted into the $\mathrm{L}_{1}$ loop (Figure 1) with a flow rate of $9.8 \mathrm{~mL} \mathrm{~min}^{-1}$.

\section{Analytical features and application}

A linear response was observed from 0.96 to $3.85 \mathrm{mmol} \mathrm{L}^{-1}$ gossypol, as described by the equation $\mathrm{A}=0.0599+0.202 \mathrm{C} ;(\mathrm{r}=0.994)$, in which $\mathrm{A}$ is the absorbance and $\mathrm{C}$ the gossypol concentration in $\mathrm{mmol} \mathrm{L}^{-1}$. The analytical features of the proposed procedure with on line extraction in a fluidized bed were evaluated, and summary values are shown in Table 2 . The detection limit ( $99.7 \%$ confidence level), the coefficient of variation $\left(\mathrm{n}=20 ; 2.41 \mathrm{mmol} \mathrm{L}^{-1}\right)$, and the sampling rate (obtained from the time interval required for 20 measurements) were estimated at $100 \mu \mathrm{mol} \mathrm{L}^{-1}, 1.90 \%$ and 30 determinations $\mathrm{h}^{-1}$, respectively. Reagent consumption per determination was estimated at $1.08 \mathrm{mg}$ of $\mathrm{Fe}\left(\mathrm{NO}_{3}\right)_{3}$, generating $20 \mathrm{~mL}$ of waste.

Table 2. Analytical features for gossypol extraction and determination

\begin{tabular}{lc}
\hline Analytical feature & Value \\
\hline Linear response / $\left(\mathrm{mmol} \mathrm{L}^{-1}\right)$ & $0.960-3.85$ \\
Detection limit / $(\mathrm{mmol} \mathrm{L}$ & -1 \\
Coefficient of variation $(\mathrm{n}=20) / \%$ & 0.107 \\
Sampling rate / (determinations $\left.\mathrm{h}^{-1}\right)$ & 1.90 \\
Reagent consumption / $(\mathrm{mg}$ per determination) & 30.0 \\
Effluent generation / $(\mathrm{mL}$ per determination) & 1.00 \\
\hline
\end{tabular}

Four cottonseed meal samples were spiked with $1.0 \%(\mathrm{~m} / \mathrm{m})$ gossypol and then analyzed using the optimal operational conditions selected for the proposed procedure. The accuracy of the measurements (Table 3) was assessed by comparing the results using a reference method based on the spectrophotometric method with $p$-anisidine and isopropyl alcohol $(80 \% \mathrm{v} / \mathrm{v})$ after extraction with acetone. ${ }^{23}$ The results agreed with those obtained by the reference procedure at the $95 \%$ confidence level.

Table 3. Main values and uncertainties for gossypol determination in spiked cottonseed meal $\left(2.45 \mathrm{mmol} \mathrm{L}^{-1}\right)$

\begin{tabular}{lcc}
\hline \multirow{2}{*}{ Sample } & \multicolumn{2}{c}{ Gossypol / $\left(\mathrm{mmol} \mathrm{L}^{-1}\right)$} \\
\cline { 2 - 3 } & Reference procedure ${ }^{24}$ & Proposed procedure \\
\hline 1 & $2.31 \pm 0.0178$ & $2.30 \pm 0.00661$ \\
2 & $2.40 \pm 0.00810$ & $2.33 \pm 0.00317$ \\
3 & $2.44 \pm 0.00577$ & $2.34 \pm 0.00340$ \\
4 & $2.22 \pm 0.00213$ & $2.25 \pm 0.0145$ \\
\hline
\end{tabular}

The analytical features of the proposed procedure were better than those obtained by other procedures for gossypol extraction and determination using cottonseed meal (Table 4). The coefficient of variation was 2 -fold lower than that observed in spectrophotometric determination with second-derivative ${ }^{8}$ and slightly higher than the observed in the HPLC ${ }^{5}$ and spectrophotometric detection with complexing. ${ }^{2}$ However, the gossypol extraction in the proposed procedure was carried out on line, which 
Table 4. Analytical features of some spectrophotometric procedures for gossypol determination in cottonseed meal

\begin{tabular}{|c|c|c|c|c|c|c|}
\hline Procedure & $\begin{array}{l}\text { Linear response / } \\
\quad\left(\mathrm{mmol} \mathrm{L}^{-1}\right)\end{array}$ & $\begin{array}{l}\text { Coefficient of } \\
\text { variation / \% }\end{array}$ & $\begin{array}{c}\text { Sampling rate / } \\
\left(\text { determinations } \mathrm{h}^{-1}\right)\end{array}$ & Solvent extraction & Solvent determination & Reference \\
\hline $\begin{array}{l}\text { Spectrophotometric } \\
\text { with iron(III) and } \\
\text { complexant }\end{array}$ & $7.71 \times 10^{-3}-1.54 \times 10^{-1}$ & 0.70 & 12 & $\begin{array}{c}\text { hexane } \\
\text { isopropyl alcohol }\end{array}$ & $\begin{array}{c}\text { hexane } \\
\text { isopropyl alcohol }\end{array}$ & 2 \\
\hline HPLC-UV & $1.92 \times 10^{-3}-1.92 \times 10^{-1}$ & - & 1.5 & $\begin{array}{l}\text { glacial acetic acid } \\
\text { dimethylformamide }\end{array}$ & $\begin{array}{c}\text { methanol:water in } \\
0.1 \% \text { phosphoric acid }\end{array}$ & 4 \\
\hline HPLC-UV & - & 1.10 & 6.0 & $\begin{array}{c}\text { acetone } \\
\text { chloroform } \\
\text { acetic acid }\end{array}$ & $\begin{array}{l}\text { methanol } \\
\text { chloroform }\end{array}$ & 5 \\
\hline $\begin{array}{l}\text { Spectrophotometric } \\
\text { with second- } \\
\text { derivative }\end{array}$ & $1.34 \times 10^{-3}-7.71 \times 10^{-3}$ & 4.00 & 2.7 & $\begin{array}{c}\text { acetone } \\
\text { chloroform } \\
\text { hydrochloric acid }\end{array}$ & $\begin{array}{l}\text { ethanol } \\
\text { diethyl ether } \\
\text { acetic acid }\end{array}$ & 8 \\
\hline $\begin{array}{l}\text { Spectrophotometric } \\
\text { with aniline }\end{array}$ & $1.54 \times 10^{-3}-1.54 \times 10^{-2}$ & - & 0.5 & hexane & hexane & 24 \\
\hline Proposed procedure & $9.64 \times 10^{-1}-3.95$ & 1.90 & 30 & ethanol $(55 \% \mathrm{v} / \mathrm{v})$ & ethanol $(55 \% \mathrm{v} / \mathrm{v})$ & this work \\
\hline
\end{tabular}

did not occur in any other procedures. The sampling rate was better than all of the procedures listed in Table 4 . The more significant increase was in comparison to the batch that used spectrophotometric determination with aniline, ${ }^{24}$ in which a sampling rate that was 60 -fold higher was observed. For the HPLC with UV detection ${ }^{4}$ and spectrophotometric determination with complexing, ${ }^{2}$ the sampling rate was, respectively, 20 and 2.5 times higher for the proposed procedure. The reagent consumption decreased considerably in comparison with the other evaluated procedures. Furthermore, the use of highly toxic solvents such as hexane, acetone, dimethylformamide and chloroform was avoided. Thus, the proposed procedure was inherently greener than those previously reported and can therefore have a highly beneficial effect through the reduction of both cost and waste.

\section{Conclusions}

The proposed procedure is a simple, fast, green and inexpensive solution for the detoxification and determination of gossypol in cottonseed meal. The analytical features of the proposed system with spectrophotometric detection and flow-injection analysis with on line extraction and fluidized bed columns were superior to those obtained by other procedures. It is a viable alternative that increases the sampling rate, and it can also be considered a greener procedure when compared to other procedures reported in the literature, reducing the amount of reagents employed and, therefore, the amount of waste generated. The on line extraction and dilution of gossypol can be implemented by the FIA, aiming to process the cottonseed meal directly.

\section{Acknowledgments}

The authors acknowledge fellowships and financial support from the Brazilian agencies Fundação de Amparo à Pesquisa do Estado de São Paulo (FAPESP, Process No. 2011/14071-1 and 2011/23498-9).

\section{References}

1. Bingchun, X.; Tao, W.; Erbao, L.; J. Anal. Chem. 2008, 63, 1078.

2. Admasu, A.; Chandravanshi, B. S.; Anal. Chem. 1984, 56, 30.

3. Abou-Donia, M. B.; Residue Rev. 1976, 16, 125.

4. Hron, R. J.; Kuk, M. S.; Abraham, G.; J. Am. Oil Chem. Soc. 1990, 67, 182.

5. Wang, M. Z.; J. Ethnopharmacol. 1987, 20, 1.

6. Wang, J.; Wang, X.; Chen, F.; Wan, P. J.; He, G.; Li, Z.; J. Agric. Food Chem. 2005, 53, 5513.

7. Mirghani, M. E. S.; Che Man, Y. B.; J. Am. Oil Chem. Soc. 2003, 80, 625 .

8. Botsoglou, N. A.; J. Agric. Food Chem. 1991, 39, 478.

9. Krug, F. J.; Ruzicka, J.; Hansen, E. H.; Analyst 1979, 104, 47.

10. Krug, F. J.; Reis, B. F.; Giné, M. F.; Zagatto, E. A. G.; Anal. Chim. Acta 1983, 151, 39.

11. Nóbrega, J. A.; Mozeto, A. A.; Alberici, R. M.; Guimarães, J. L.; J. Braz. Chem. Soc. 1995, 6, 327.

12. Rocha, F. R. P.; Reis, B. F.; Zagatto, E. A. G.; Lima, J. L. F. C.; Lapa, R. A. S.; Santos, J. L. M.; Anal. Chim. Acta 2002, 468, 119.

13. Reis, B. F.; Morales-Rubio, A.; de la Guardia, M.; Anal. Chim. Acta 1999, 392, 265.

14. Zamora, L. L.; Calatayud, J. M.; Talanta 1993, 40, 1067.

15. Teixeira, L. S. G.; Rocha, F. R. P.; Korn, M.; Reis, B. F.; Ferreira, S. L. C.; Costa, A. C. S.; Anal. Chim. Acta 1999, 383, 309. 
16. Sánchez-Dasi, M. J.; Garrigues, S.; Cervera, M. L.; de la Guardia, M.; Anal. Chim. Acta 1998, 361, 253.

17. Bouhsain, Z.; Garrigues, S.; de la Guardia, M.; Analyst 1997, $122,441$.

18. de la Guardia, M.; Khalaf, K. D.; Carbonell, V.; Morales-Rubio, A.; Anal. Chim. Acta 1995, 308, 462.

19. Peris-Cardells, E.; Terol, J.; Mauri, A.; de la Guardia, M.; Pramauro, E.; J. Environ. Sci. Health B 1993, 28, 431.

20. de la Guardia, M.; Khalaf, K. D.; Hansan, B. A.; Morales-Rubio, A.; Carbonell, V.; Analyst 1995, 120, 231.
21. AOCS; Official Method Ba 8-58 in Official and Tentative Methods of Analysis, $3^{\text {rd }}$ ed.; American Oil Chemists' Society: Chicago, IL, 1985b.

22. Zagatto, E. A. G.; Arruda, M. A. Z.; Jacintho, A. O.; Mattos, I. L.; Anal. Chim. Acta 1990, 234, 153.

23. http://cottonseed.org/publications/Calhoun $\% 20$ Nutrition $\% 20$ Values.pdf, accessed in November 2016.

24. Smith, F. H.; Ind. Eng. Chem., Anal. Ed. 1946, 18, 41.

Submitted: February 1, 2017

Published online: March 24, 2017 